\title{
Mariana L. R. Dantas. Black townsmen: urban slavery and freedom in the eighteenth-century Americas
}

Douglas Cole Libby*

New York: Palgrave Macmillan, 2008. 280p.

Há cerca de três décadas os estudos comparativos das várias regiões do Novo Mundo consideradas como escravistas andam em descrédito entre a maioria dos historiadores especialistas no tema. A renovação historiográfica, iniciada nos Estados Unidos no final da década de 1960, julgava como simplista e inadequada a abordagem que enfatizava as diferenças entre as sociedades escravistas ibero-americanas e anglo-saxônicas, particularmente no que diz respeito à história das suas instituições e culturas distintas. ${ }^{1}$ Da mesma forma, rejeitava como mecanicistas as análises que insistiam nas semelhanças, naquelas mesmas sociedades, da natureza da escravidão como um sistema de exploração econômica. ${ }^{2}$ Já a mais conhecida tentativa revisionista de redirecionar os estudos comparativos para a problemática das classes constituintes dos regimes escravistas ${ }^{3}$ acabou sucumbindo, apesar da matriz marxista compartilhada, diante da crescente influência de E. P. Thompson sobre os estudiosos da escravidão e da consequente preocupação em desvelar o escravo como agente de sua própria história. Desde então, vem prevalecendo a tendência de concentrar os esforços em pesquisas bem delimitadas, seja pelas temáticas, ${ }^{4}$ seja em termos regionais, ${ }^{5}$ tendência essa claramente reforçada pela progressiva consolidação das várias correntes da História Social da Cultura. E, é inegável que o resultado tem sido o enriquecimento quase que imensurável da produção em torno da escravidão moderna, erguendo-a a uma posição de grande destaque na historiografia brasileira, caribenha, norte-americana e, de maneira menos impactante, na da América Hispânica continental. Ao mesmo tempo e correlato à crescente especialização dos estudos do escravismo, vem-se assistindo ao surgimento da História da África, cada vez mais aprofundada e nitidamente vinculada aos rumos da História Mundial.

$\mathrm{Na}$ realidade, a ousadia de Mariana Dantas em querer retomar o cami-

* Departamento de História, UFMG. Pesquisador CNPq. Av. Antônio Carlos, 6627, Pampulha. 31270-901 Belo Horizonte - MG - Brasil. dclibby@fafich.ufmg.br. 
nho comparativo acabou gerando resultados muito positivos exatamente porque a autora conhece a fundo a dinâmica da historiografia contemporânea, particularmente no que diz respeito ao desenrolar dos estudos da escravidão moderna. O domínio e o uso comedido da literatura relevante - a teórica, a metodológica e a temática - são realmente impressionantes. Serão poucos os leitores que não irão descobrir, nas citações do texto, desconhecidas, porém sedutoras, publicações. Já a envergadura e engenhosidade das pesquisas de campo, tanto as empreendidas nos arquivos mineiros e portugueses, quanto aquelas realizadas nos arquivos municipais e eclesiásticos de Baltimore, do estado de Maryland e com o material censitário produzido pela jovem república norte-americana, demonstram o talento e a capacidade invejáveis de uma historiadora que, afinal, encontra-se ainda no início da sua carreira. Trata-se de um sólido embasamento empírico, ao qual se remete, de forma ponderada, para sustentar os argumentos apresentados ao longo do livro.

A principal proposta da obra é a de procurar entender como as pessoas de origem ou ascendência africana contribuíram para formar, em Sabará e em Baltimore, um ambiente urbano do qual pudessem perceber benefícios. A premissa é que os africanos e seus descendentes, ao negociarem possíveis transições da escravidão para a liberdade, teriam concorrido para determinar a trajetória histórica dos dois centros urbanos de quatro maneiras básicas: ajudaram a sustentar o crescimento demográfico e econômico de ambos; renegociaram os arranjos em torno da mão de obra urbana; ajudaram a dar forma às estruturas sociais urbanas e influenciaram os padrões de ocupação do solo urbano e da posse de propriedades urbanas. "Através de sua presença, suas atividades e experiências, os indivíduos de origem e descendência africanas, junto com os demais habitantes, definiram o caráter destas duas vilas". É convicção da autora que "uma melhor compreensão do processo pelo qual escravos e seus companheiros livres e libertos permeavam, das franjas ao núcleo, o tecido dessas sociedades urbanas fará avançar nosso entendimento da participação intrínseca e intensa deles no processo histórico da formação e do desenvolvimento de diversas sociedades nas Américas". ${ }^{6}$

É o cenário urbano, portanto, que serve como base para a comparação de duas realidades, em princípio, bastante distintas. No balanço, no entanto, pode-se afirmar que as semelhanças prevalecem sobre as diferenças, principalmente no que diz respeito às contribuições decisivas dos escravos e libertos à construção das duas cidades. Mas, havia diferenças, é claro. Em termos cronológicos, por exemplo, a distinção é clara. O surto de crescimento de Sabará se deu em função da rápida consolidação da mineração aurífera durante a 
primeira metade do século XVIII, embora não se possa falar de involução ou decadência ao se referir as últimas décadas do Setecentos. Apesar dos esforços das autoridades coloniais, o desenvolvimento de Baltimore somente acelerou a partir da década de 1760, quando se firmou na sua posição de entreposto do comércio e transporte do trigo, cujo cultivo passara a se espalhar pelos campos de boa parte de Maryland.

A ampla diversificação ocupacional da mão de obra escrava e liberta marcou a realidade das duas cidades ao longo do Setecentos. Ao enfatizar este ponto com relação a Sabará, com seu verdadeiro exército de escravos de ganho (inclusive os faiscadores) e de aluguel e de escravas de tabuleiro, vai se fundamentando uma interpretação da História Colonial de Minas que insiste na importância da divisão social do trabalho e, portanto, das forças de mercado para a consolidação da sociedade e da economia da Capitania. ${ }^{7}$ Trata-se de uma substancial contribuição mineira para o questionamento da validade do modelo do Sistema Colonial. No caso de Baltimore, confirma-se, mais uma vez, que a vocação do trabalho escravo não era única e exclusivamente agrícola. Afinal, o braço cativo (e liberto) foi fundamental para a indústria naval que tanto contribuiu para o desenvolvimento da cidade. Mais importante para a autora, no entanto, é que toda essa diversificação ampliou o leque de possibilidades de negociação no mercado de trabalho de escravos, forros e livres de origem ou ascendência africana.

Essa ampliação de oportunidades foi fundamental, em ambas as localidades, para que alguns escravos alcançassem sua libertação. No evento, havia alguns contrastes bem interessantes. Na urbe mineira as mulheres prevaleciam entre os alforriados, enquanto as libertações pagas superavam as espontâneas e as condicionadas (geralmente, por tempo adicional de serviço). Em Baltimore os homens predominavam entre os libertos, e as manumissões condicionadas eram as mais comuns. Mesmo assim, as histórias individuais de libertação e da vida forra são parecidas, independentemente da geografia. Com efeito, essas reconstruções de vida constituem o elemento mais precioso de Black townsmen, pois a autora é mestra na arte de pintar o quadro geral com pinceladas alimentadas pelo cotidiano da micro-história. Pode-se afirmar que é aqui que Mariana Dantas acaba por criar um modelo original e profícuo de se (re)fazer a história comparativa e daí que sua obra se torna uma leitura obrigatória para aqueles que se interessam pela História Colonial e/ou pelos estudos do escravismo nas Américas.

Definir o urbano no contexto da História Colonial de qualquer parte da Américas é, a nosso ver, uma tarefa inacabada. Como adverte Kátia Mattoso, 
ao tratar de Salvador já no século XIX, é extremamente difícil distinguir entre o urbano e o rural, tendo em vista a estreiteza dos múltiplos vínculos entre as duas instâncias ${ }^{8}$ - advertência essa que cabe aos dois casos tratados em Black townsmen. Uma discussão mais sistematizada dessa questão teria enriquecido a obra. Da mesma forma, teria sido elucidativo tecer mais considerações acerca do conceito do escravismo, tal como utilizado pela autora. A importância de tal exercício analítico se dá exatamente em função da natureza comparativa do livro. Para o período enfocado, Sabará e todo seu vasto termo inquestionavelmente constituíam uma região plenamente escravista. Pode-se concluir o mesmo com relação a Baltimore e seu county? Às vezes parece-nos que as diferenças destacadas pela autora poderiam ser atribuídas à natureza comparativamente menos escravista desse porto situado às margens da baía de Chesapeake. Parafraseando um trabalho recente, ${ }^{9}$ pode-se pensar em Baltimore como uma cidade com escravos ou como uma cidade escravista? Prosseguindo nesta mesma linha, poder-se-ia perguntar até que ponto graus distintos de intensidade do tráfico negreiro estariam a explicar várias das diferenças detectadas ao longo das análises mais pormenorizados da obra. Apesar de sua localização no longínquo interior das Minas, ao longo do século XVIII, Sabará foi regularmente suprida de novas "peças" africanas, através tanto de Salvador, quanto do Rio de Janeiro. Já o tráfico negreiro para Baltimore foi esporádico e muito menos intenso, chegando até mesmo a ser proibido por certo tempo no apagar do Setecentos. Para senhores de escravos acostumados a contar com a ampla disponibilidade de africanos recém-desembarcados, a substituição de um escravo alforriado poderia ser considerada algo corriqueiro. Daí que, no caso de Sabará e de boa parte da América Portuguesa, as práticas de alforria nitidamente passaram a fazer parte das estratégias de controle senhorial, sem deixar de representar conquistas primordiais para os cativos e para toda a comunidade de origem ou ascendência africana. Levantam-se tais questões não como críticas, mas a título de instigar Mariana Dantas a nos brindar com novos textos do mesmo brilho que Black townsmen.

\section{NOTAS}

${ }^{1} \mathrm{O}$ pioneiro dessa abordagem foi Gilberto Freyre, especialmente no seu Casa-grande e senzala, publicado em inglês como The masters and the slaves (trad. Samuel Putnam, New York: Knopf, 1946). Freyre serviu como inspiração para, entre muitas outras, as seguintes obras: TANNENBAUM, Frank. Slave and citizen: the Negro in the Americas. New York: Knopf, 1947; ELKINS, Stanley. Slavery: a problem in American institutional and intellec- 
tual life. Chicago: University of Chicago Press, 1959; KLEIN, Herbert. Slavery in the Americas: a comparative study of Virginia and Cuba. Chicago: University of Chicago Press, 1967.

${ }^{2}$ Cf. WILLIAMS, Eric. Capitalism \& slavery. Chapel Hill: The University of North Carolina Press, 1944; HARRIS, Marvin. Patterns of race in the Americas. New York: Walker \& Company, 1964; DAVIS, David Brion. The problem of slavery in western culture. Ithaca: Cornell University Press, 1966.

${ }^{3}$ GENOVESE, Eugene D. The world the slaveholders made: two essays in interpretation. New York: Pantheon Books, 1969.

${ }^{4}$ É sintomático, no caso, que também em 1969 Curtin tenha inaugurado um novo olhar, desincumbido das denúncias moralistas, sobre o tráfico negreiro internacional. CURTIN, Philip. The Atlantic slave trade: a census. Madison: The University of Wisconsin Press, 1969.

${ }^{5}$ Sem dúvida, a historiografia norte-americana, impulsionada pelos tumultos raciais do período, inicialmente liderou a tendência de voltar a focalizar os casos nacionais. Ver, sobretudo, o próprio Genovese, Roll, Jordan, Roll: the world the slaves made. New York: Pantheon Books, 1974; FOGEL, Robert W.; ENGERMAN, Stanley L. Time on the cross: the economics of American negro slavery. Boston: Little Brown, 1974; GUTMAN, Herbert. The black family on slavery and freedom, 1750-1925. New York: Pantheon Books, 1976.

${ }^{6}$ DANTAS, p.3.

${ }^{7}$ Cf. SILVA, Flávio Marcus. Subsistência e poder: a política de abastecimento alimentar nas Minas Setecentistas. Belo Horizonte: Ed. UFMG, 2008.

${ }^{8}$ MATTOSO, Kátia M. de Queirós. Bahia: a cidade do Salvador e seu mercado no século XIX. São Paulo: Hucitec, 1978. p.26-28, 115-127.

${ }^{9}$ BERLIN, Ira. Generations of captivity: a history of Afro-American slaves. Cambridge (MA), The Belknap Press, 2003. p.8-12.

Resenha recebida em janeiro de 2009. Aprovada em fevereiro de 2009. 